\title{
Experiências descontínuas de trabalho: uma análise a partir da dinâmica de admissões e de desligamentos nos mercados formais de cidades médias do Rio Grande do Sul
}

Discontinuous work experiences: an analysis based on the dynamics of admissions and disconnections in the formal markets of medium-sized cities in Rio Grande do Sul

\section{Marco Andre Cadoná}

Universidade de Santa Cruz do Sul - UNISC - Santa Cruz do Sul - Rio Grande do Sul - Brasil

\begin{abstract}
$\longrightarrow$
Resumo: $\mathrm{O}$ artigo dedica-se à análise de um aspecto fundamental da flexibilidade contratual presente em mercados de trabalho: a descontinuidade nos vínculos empregatícios. Tomando como referência os dados do CAGED (Cadastro Geral de Empregados e Desempregados), sobre a dinâmica de admissões e de desligamentos nos mercados de trabalho de dez cidades médias gaúchas, no período entre 2011 e 2017, a análise indica que experiências descontinuas de vínculos empregatícios são expressões das condições precárias de trabalho que vivenciam parcelas significativas de trabalhadores nas cidades médias no Rio Grande do Sul.
\end{abstract}

Palavras-chave: Trabalho. Mercado de trabalho. Cidades médias. Vínculos empregatícios. Flexibilidade contratual.

\begin{abstract}
The article is devoted to the analysis of a fundamental aspect of the contractual flexibility present in labor markets: the discontinuity in employment relations. Based on data from the CAGED (General Register of Employed and Unemployed), on the dynamics of admissions and dismissals in the labor markets of ten medium-sized gauchas cities in the period between 2011 and 2017, the analysis indicates that discontinuous experiences of employment relationships are expressions of the precarious work conditions experienced by significant portions of workers in the middle cities in Rio Grande do Sul.
\end{abstract}

Keywords: Job. Job market. Medium cities. Employment links. Contractual flexibility. 


\section{Introdução.}

Um fenômeno importante e observado num período recente no Brasil, mesmo quando os resultados das políticas governamentais foram expressivos nos mercados de trabalho, impulsionando o crescimento dos empregos formais e o aumento do poder de compra dos salários, está relacionado com a alta rotatividade da força-de-trabalho.

A rotatividade no mercado de trabalho expressa um movimento recorrente de substituição de parte da força-de-trabalho, utilizada num determinado período, através de demissões e de admissões de trabalhadores (DIEESE, 2017). Para as empresas capitalistas, desde que seus índices não prejudiquem a produtividade do trabalho e do capital, a rotatividade da força-de-trabalho é uma "movimentação das pessoas no interior da organização", um "contínuo fluxo do capital humano dentro da organização", envolvendo admissões, desligamentos, transferências, afastamento por aposentadoria e/ou morte (CHIAVENATTO, 2004, p. 373). Para os governos, não raras vezes representa um problema que implica gastos orçamentários visando garantir a mínima proteção aos trabalhadores entre os períodos de desligamento e de nova admissão. Para os trabalhadores, no entanto, a rotatividade é uma condição precária de inserção no mercado de trabalho, na medida em que dificulta a obtenção de uma qualificação num posto de trabalho, corrói a renda do trabalho, compromete o tempo de contagem para aposentadoria, impede a consolidação de vínculos com uma comunidade de trabalho, cria a necessidade de uma nova colocação no mercado de trabalho na condição de mercadoria força-de-trabalho.

É importante destacar que, no contexto da reestruturação do capitalismo ocorrida a partir das últimas décadas do século $X X$, a rotatividade nos empregos é expressão da ainda maior "flexibilidade" no uso da força-de-trabalho. Não se trata de uma "disfunção" presente nas relações sociais capitalistas, mas, antes, uma condição histórica necessária para a reprodução do capital. O interesse em um trabalhador que está disponível, de acordo com as necessidades colocadas pela dinâmica de valorização do capital, é uma característica importante dessa fase mais recente de organização capitalista do trabalho. O que se observa, pois, tanto no âmbito da organização dos processos produtivos quanto no âmbito das "novas legislações do trabalho", é a exacerbação da intermitência do trabalho.

Os trabalhadores desse precário mundo do trabalho estão submetidos a formas contratuais que, legitimadas pela ação coercitiva do Estado capitalista ("as novas legislações trabalhistas"), colocam à disposição do capital diferentes formas de "contratação flexível", configurando-se um contexto histórico em que o trabalho com jornada parcial, o contrato com prazo determinado, o trabalho temporário, o trabalho por tarefa, o contrato por teletrabalho, a suspensão temporária do contrato do trabalho, o trabalho intermitente, deixaram de ser modalidades atípicas de uso da força de trabalho (ANTUNES, 2018).

No Brasil e num período mais recente, um exemplo ilustrativo e emblemático do aprofundamento desse processo histórico de "flexibilização" no uso da força-de-trabalho ocorreu com a legalização do trabalho intermitente, vigente desde a reforma trabalhista realizada pelo governo de Michel Temer, em 2017. Aquela reforma, aliás, inseriu-se num contexto de hegemonia do ideário neoliberal na condução das mudanças na legislação trabalhista no Brasil, legitimando ações de desregulamentação (retirada de direitos até então assegurados), de privatização (transferência das decisões sobre relações do trabalho para o mercado) e de flexibilização (possibilidade de determinadas relações de trabalho serem definidas e redefinidas ao sabor das modificações nos interesses dos agentes do capital) (AUTOR, 2016). É nessa direção que a reforma aprovada assegurou que o acordado prevaleça sobre o legislado, que a jornada de trabalho e as férias sejam flexibilizadas, que mulheres grávidas e lactantes possam trabalhar em condições insalubres; e que o trabalho possa ser intermitente, uma modalidade que afirma a possibilidade de um contrato de trabalho não contínuo, assim definido no artigo 443 da Consolidação das Leis Trabalhistas (CLT): trabalho 
que ocorre "com alternância de períodos de prestação de serviços e de inatividade, determinados em horas, dias ou meses, independentemente do tipo de atividade do empregado e do empregador" (CLT, 2017).

Configura-se no Brasil, nesse sentido, um contexto histórico de precarização do trabalho, que se manifesta através de diferentes formas de insegurança para os trabalhadores: uma insegurança nos mercados de trabalho, dada a permanência de índices significativos de desemprego (em dezembro de 2018, a taxa de desemprego no País, segundo dados do IBGE, chegou aos 11,6\%, atingindo 12,2 milhões de pessoas) (IBGE, 2018); uma insegurança nos empregos, que decorre da presença significativa de empregos vulneráveis (autônomo para o público e empregados sem carteira assinada, empregos temporários, de meio-expediente, intermitentes); uma insegurança na renda, em virtude das dinâmicas de corrosão dos salários, presentes principalmente em períodos de crise econômica e de desemprego, mas também de formas de ocupação com baixas remunerações salariais; uma insegurança na contratação do trabalho, decorrente da presença de parcelas significativas de trabalhadores que são mantidos afastados de uma proteção legal ao trabalho (DIEESE, 2012).

E é nesse contexto de precarização do trabalho que no presente artigo é analisada a dinâmica de admissões e de desligamentos, observada nos mercados de trabalhos de cidades médias no Rio Grande do Sul, no período entre 2011 e 2017. Tomando como referência empírica as admissões e os desligamentos ocorridos nos mercados de trabalho de dez cidades gaúchas, localizadas fora da Região Metropolitana de Porto Alegre e cujos municípios têm populações superiores aos cem mil habitantes (conforme estimativas do IBGE, para o ano de 2017), ${ }^{1}$ a análise foca na descontinuidade dos vínculos empregatícios como expressão da flexibilidade contratual que se configura enquanto estratégia de dominação sobre os trabalhadores.

Trata-se, portanto, de uma análise sobre precarização do trabalho, manifesta nas descontinuidades dos vínculos empregatícios, mas também sobre as dinâmicas de organização dos mercados de trabalho em cidades médias. Cidades que, importante destacar, não se definem somente a partir da referência quantitativa (cidades que têm entre 100 e 500 mil habitantes, por exemplo), mas, fundamentalmente, por estarem situadas fora das regiões metropolitanas, apresentarem "potenciais de absorção" de investimentos (pois possuem "algum tipo de economia de aglomeração"; ganhos de produtividade atribuídos à aglomeração geográfica de populações e/ou de atividades econômicas), e, ao mesmo tempo, não incorrerem em deseconomias de aglomeração, típicas das grandes metrópoles" (PEREIRA, LEMOS, 2003, p.127). Mais do que isso, são cidades que têm importância regional, pois são referências para um determinado número de municípios localizados num dado lugar identificado no interior de uma subnação, ao mesmo tempo em que articulam esses municípios com circuitos nacionais e mesmo internacionais de produção e de poder político (SPOSITO, 2007).

Para a análise indicada são considerados os dados do CAGED que, importante ter presente, não permitem avaliar se a movimentação referente aos desligamentos e às admissões está diretamente vinculada a mudanças que ocorrem num mesmo posto de trabalho, mas, de qualquer modo, permitem observar a rotação da força de trabalho, ou seja, o rodízio de trabalhadores que se observa nos mercados
Considerando as estimativas do IBGE para o ano de 2017, dez municípios gaúchos localizados fora da Região Metropolitana de Porto Alegre tinham mais de 100 mil habitantes: Caxias do Sul, com 479.236 habitantes; Pelotas, com 343.651 habitantes; Santa Maria, com 278.455 habitantes; Rio Grande, com
208.641 habitantes; Passo Fundo, com 198.799 habitantes; Santa Cruz do Sul, com 127.429 habitantes; Uruguaiana, com 125.507 habitantes; Bagé, com 121.986 habitantes; Bento Gonçalves, com 115.069 habitantes; e Erechim, com 102.906 habitantes (IBGE, 2017). 
de trabalho, devido ao movimento de admissões e de desligamentos de trabalhadores.

Os dados do CAGED permitem analisar a dinâmica mensal de admissões e de desligamentos, em todos os municípios do País. Tanto de forma agregada, ou seja, com a identificação do número de admissões e de desligamentos, no total do município e por setor de atividade econômica. Quanto de forma desagregada, com a identificação das modalidades de admissões (primeiro emprego; reemprego; reintegração; contrato de trabalho por prazo determinado; transferência administrativa) e das modalidades de desligamentos (dispensa sem justa causa; dispensa com justa causa; a pedido; término do contrato; aposentadoria; morte; término de contrato temporário; transferência).

Nesse sentido, no que diz respeito aos desligamentos, os dados do CAGED permitem analisar dois tipos de demissões: aquelas que ocorrem por razões diretamente vinculadas a razões dos trabalhadores (pedido de demissão, aposentadoria, falecimento) e aquelas que ocorrem por razões diretamente relacionadas a razões das empresas (demissões ou por justa causa, ou sem justa causa, ou por término de contrato).

Após a apresentação dos dados relacionados à dinâmica de admissões e de desligamentos nas cidades médias gaúchas, a discussão sobre a flexibilidade contratual será retomada, numa perspectiva de ampliar a compreensão de como essa condição de precarização no trabalho está presente nos mercados de trabalho das cidades médias no Rio Grande do Sul.

\section{A dinâmica de admissões e de desligamentos nas cidades médias gaúchas no período entre 2011 e 2017.}

Os dez municípios cujas sedes são as cidades médias investigadas neste trabalho possuíam, em janeiro de 2018, um total de 513.652 empregos formais. Desse total de empregos, a grande maioria era constituída por empregos com contratos de trabalho regidos pela CLT (Consolidação das Leis do Trabalho), também denominados de vínculos celetistas. São empregos que estão, predominantemente, no setor privado, embora no setor público também possa ser encontrado esse tipo de contrato (IBGE, 2016, p. 23).

A análise da dinâmica de admissões e de desligamentos nos mercados de trabalho das cidades investigadas permite perceber que a flexibilidade contratual nessas cidades é bastante significativa, expressando uma condição histórica de trabalho que, para muitos trabalhadores, implica empregos de curta duração e trajetórias profissionais caracterizadas por constantes interrupções, com a consequente necessidade de buscar uma nova ocupação. Essas são algumas das características que podem ser observadas nos dois quadros a seguir apresentados (Quadros 01 e 02). 
QUADRO 01: Dinâmica de Admissões e de Desligamentos nos mercados formais de trabalho dos municípios investigados (2011 - 2014)

\begin{tabular}{|l|c|c|c|c|c|c|}
\hline \multirow{2}{*}{ Anos } & \multicolumn{2}{|c|}{2015} & \multicolumn{2}{c|}{2016} & \multicolumn{2}{c|}{2017} \\
\cline { 2 - 7 } Cidades & A. & D. & A. & D. & A. & D. \\
\hline Bagé & 5.902 & 6.189 & 5.366 & 5.560 & 5.773 & 5.774 \\
B. Gonçalves & 19.122 & 21.020 & 14.983 & 16.604 & 15.133 & 15.472 \\
Caxias do Sul & 63.101 & 77.181 & 54.755 & 61.652 & 56.584 & 57.199 \\
Erechim & 15.619 & 17.584 & 12.393 & 15.208 & 12.951 & 12.649 \\
Passo Fundo & 26.464 & 27.704 & 23.218 & 23.967 & 25.126 & 24.200 \\
Pelotas & 27.375 & 30.228 & 24.216 & 25.937 & 23.480 & 24.292 \\
Rio Grande & 18.373 & 21.951 & 15.794 & 20.803 & 14.095 & 16.174 \\
S. Cruz do Sul & 24.701 & 26.375 & 20.270 & 20.755 & 21.520 & 21.494 \\
Santa Maria & 26.388 & 27.692 & 23.021 & 23.418 & 24.642 & 23.890 \\
Uruguaiana & 6.959 & 7.202 & 6.329 & 6.556 & 6.574 & 6.138 \\
\hline TOTAL & 234.004 & 263.126 & 200.345 & 220.460 & 205.878 & 207.282 \\
\hline
\end{tabular}

Fonte: MTE/CAGED, 2018. Dados organizados pelo autor. Legendas: A - Admissões; D - Desligamentos

QUADRO 02: Dinâmica de Admissões e de Desligamentos nos mercados formais de trabalho dos municípios investigados (2015 - 2017)

\begin{tabular}{|l|c|c|c|c|c|c|c|c|}
\hline \multirow{2}{*}{ Anos } & \multicolumn{2}{|c|}{2011} & \multicolumn{2}{c|}{2012} & \multicolumn{2}{c|}{2013} & \multicolumn{2}{c|}{2014} \\
\cline { 2 - 9 } Cidades & A. & D. & A. & D. & A. & D. & A. & D. \\
\hline Bagé & 7.390 & 6.678 & 7.069 & 6.135 & 7.128 & 6.701 & 7.475 & 7.432 \\
B. Gonçalves & 22.940 & 20.778 & 23.485 & 22.160 & 25.899 & 23.080 & 24.899 & 24.208 \\
Caxias do Sul & 105.260 & 98.011 & 99.971 & 99.578 & 100.689 & 97.842 & 89.331 & 93.011 \\
Erechim & 23.949 & 21.381 & 21.909 & 21.661 & 24.632 & 23.376 & 21.471 & 22.289 \\
Passo Fundo & 29.660 & 26.936 & 30.450 & 29.344 & 32.077 & 30.028 & 32.259 & 31.653 \\
Pelotas & 32.171 & 28.779 & 32.747 & 31.927 & 35.200 & 32.970 & 35.240 & 34.499 \\
Rio Grande & 20.360 & 17.408 & 31.572 & 24.830 & 41.773 & 41.290 & 33.172 & 32.271 \\
S. Cruz do & 30.854 & 29.242 & 28.988 & 27.037 & 30.873 & 30.028 & 31.608 & 30.478 \\
Sul & 28.639 & 25.899 & 29.704 & 27.605 & 31.665 & 29.153 & 31.957 & 31.785 \\
Santa Maria & 7.482 & 7.753 & 7.589 & 7.684 & 7.710 & 7.448 & 7.591 & 7.633 \\
Uruguaiana & & & & & & & & \\
\hline TOTAL & 308.705 & 282.865 & 313.484 & 297.961 & 336.767 & 321.916 & 315.003 & 315.259 \\
\hline
\end{tabular}

Fonte: MTE/CAGED, 2018. Dados organizados pelo autor. Legendas: A - Admissões; D Desligamentos

Uma primeira questão que pode ser analisada a partir dos dados apresentados nesses dois quadros está relacionada à dinâmica de criação de empregos no período de estudo. Nessa direção, destaque-se que as cidades médias gaúchas acompanharam tendências observadas em nível nacional. No Brasil, no período entre 2002 e 2014 foram criados aproximadamente 20 milhões de empregos formais, caracterizando uma "fase exitosa" em termos de criação desse tipo de emprego (DIEESE, 2016, p. 11). No entanto, já a partir do segundo semestre de 2014 os estoques de empregos formais sofreram fortes quedas, "registrando diminuição de 4,7\% [...] e 4,5\% [...] entre o segundo trimestre de 2014 e o primeiro 
trimestre de 2016" (SOUEN, CAMPOS, 2017, p. 54). Nas 10 cidades médias investigadas, o número de admissões também cresceu até 2014, mas apresentou uma queda significativa a partir de 2015: de uma média anual de 349.809 admissões no período entre 2011 e 2014 para uma média anual de 237.684 admissões no período entre 2015 e 2017.

Ao mesmo tempo que as admissões foram diminuindo, as diferenças entre admissões e desligamentos passaram a ser mais favoráveis para essas últimas. Os dados apresentados dos quadros anteriores indicam, nesse sentido, que no período entre 2011 e 2013 o número de admissões superou o número de desligamentos: diferença pró admissões de 28.875 em 2011, de 16.153 em 2012 e de 18.826 em 2013. A partir de 2014, no entanto, a situação se inverteu e o número de desligamentos passou a superar o número de admissões: diferença pró desligamentos de 256 em 2014, de 30.174 em 2015, de 20.164 em 2016 e de 1.419 em 2017.
Uma segunda questão a ser destacada a partir dos dados até então apresentados está relacionada às especificidades dos mercados de trabalho das cidades médias gaúchas. Ainda que, em linhas gerais, seus mercados de trabalho tenham dinâmicas próximas àquela observada em nível nacional, um detalhamento dos dados permite perceber particularidades que decorrem do processo histórico de desenvolvimento local e regional das cidades médias investigadas.

Particularidades que ganham evidência quando, por exemplo, a dinâmica de admissões e de desligamentos é analisada num mesmo ano. Como é o caso dos dados apresentados no quadro a seguir, que considera o ano de 2017 e permite um acompanhamento trimestral das admissões e dos desligamentos na dez cidades investigadas (Quadro 03).

QUADRO 03: Dinâmica de admissões e de desligamentos no ano de 2017 nas cidades médias do Rio Grande do Sul, por movimentação trimestral

\begin{tabular}{|l|c|c|c|c|c|c|c|c|}
\hline $\begin{array}{l}\text { Períodos do } \\
\text { ano }\end{array}$ Cidades & \multicolumn{2}{|c|}{$\begin{array}{c}\text { Primeiro } \\
\text { trimestre }\end{array}$} & \multicolumn{2}{c|}{$\begin{array}{c}\text { Segundo } \\
\text { trimestre }\end{array}$} & \multicolumn{2}{c|}{$\begin{array}{c}\text { Terceiro } \\
\text { trimestre }\end{array}$} & \multicolumn{2}{c|}{ Quarto trimestre } \\
\cline { 2 - 9 } & A. & D. & A & D. & A. & D. & A. & D. \\
\hline Bagé & 1.603 & 1.590 & 1.422 & 1.497 & 1.452 & 1.358 & 1.296 & 1.329 \\
Bento & 4.413 & 4.337 & 3.590 & 3.836 & 3.934 & 3.753 & 3.196 & 3.546 \\
Gonçalves & 16.874 & 14.754 & 12.799 & 13.816 & 14.056 & 14.126 & 12.855 & 14.503 \\
Caxias do Sul & 3.661 & 3.406 & 3.023 & 3.187 & 3.525 & 2.901 & 2.742 & 3.155 \\
Erechim & 7.332 & 6.276 & 5.936 & 6.679 & 6.141 & 5.842 & 5.717 & 5.403 \\
Passo Fundo & 5.971 & 6.392 & 5.571 & 6.133 & 5.293 & 5.227 & 6.645 & 6.540 \\
Pelotas & 3.760 & 4.263 & 3.579 & 3.780 & 3.575 & 3.525 & 3.181 & 4.606 \\
Rio Grande & 8.898 & 4.208 & 4.661 & 4.244 & 4.030 & 9.041 & 3.931 & 4.001 \\
Santa Cruz do & 6.368 & 5.993 & 5.797 & 5.869 & 6.129 & 5.935 & 6.348 & 6.093 \\
Sul & 1.885 & 1.489 & 1.501 & 1.813 & 1.573 & 1.426 & 1.615 & 1.410 \\
Santa Maria & & & & & & & & \\
Uruguaiana & & & & & & & & \\
\hline Total & 60.765 & 52.708 & 47.879 & 50.854 & 49.708 & 53.134 & 47.526 & 50.586 \\
\hline
\end{tabular}

Fonte: MTE/CAGED, 2018. Dados organizados pelo autor. Legendas: A - Admissões; $\mathrm{D}$ - Desligamentos 
Em linhas gerais, os dados apresentados neste último quadro permitem perceber que, no conjunto das cidades investigadas, o ano de 2017 terminou com um saldo de desligamentos maior daquele observado nas demissões: foram 205.878 admissões e 207.282 desligamentos ao longo daquele ano.

Porém, sob o ponto de vista das especificidades locais e regionais, algumas diferenças são perceptíveis. A primeira delas está relacionada às cidades de Pelotas e de Rio Grande, as duas únicas nas quais o número de desligamentos foi superior ao número de admissões no primeiro trimestre. A segunda delas está relacionada à cidade de Santa Cruz do Sul, onde o número de admissões é significativamente superior no primeiro trimestre, invertendo-se essa situação no terceiro trimestre. A terceira delas refere-se às cidades de Passo Fundo, de Pelotas, de Santa Maria e de Uruguaiana, onde se observa que, no quarto semestre, o número de admissões foi superior ao número de desligamentos, num movimento que destoa do que é observado nas demais cidades.

Nos limites do presente artigo não é possível aprofundar a análise dessas diferentes realidades, com destaque ao modo como a dinâmica de desenvolvimento regional condiciona a organização dos mercados de trabalho. De qualquer forma e a título de ilustração, é importante destacar que em cidades como Passo Fundo, Pelotas, Santa Maria e Uruguaiana os empregos vinculados ao comércio têm grande importância, do que decorre uma dinâmica de admissões e de desligamentos onde a abertura de vagas no último trimestre pode ser explicativa de um saldo positivo de empregos nesse último período do ano. $^{2}$

Mais elucidativo, ainda, é a situação da cidade de Santa Cruz do Sul, onde as admissões são sempre maiores nos primeiros semestres, enquanto que nos segundos semestres são os desligamentos que são

2 Considerando os dados do CAGED, os empregos vinculados ao setor do comércio correspondiam a $32,8 \%$ em Uruguaiana, a 27,2\% em Passo Fundo, a $31,8 \%$ em Pelotas e a $28,8 \%$ em Santa Maria do total maiores (tal como indicado no quadro 03, tomando-se como referência o ano de 2017). Mais do que uma contingência, os dados de 2017 são expressões de uma característica fundamental do mercado de trabalho de Santa Cruz do Sul: a sazonalidade da dinâmica de admissões e de desligamento, em grande parte decorrente do modo como a indústria fumageira organiza sua produção no município.

O tabaco produzido pelos agricultores (em diferentes regiões do Rio Grande do Sul e, mesmo, de Santa Catarina e do Paraná) chega nas indústrias localizadas em Santa Cruz do Sul no início de cada ano. É a partir do início do ano, portanto, que se observa uma maior demanda de trabalhadores na cidade. Muitos trabalhadores, então, são contratados para um trabalho temporário, que (com algumas pequenas variações) dura em torno de seis ou sete meses. Depois desse período, que ocorre nos meses de julho/agosto, as indústrias demitem os trabalhadores contratados no início do ano, abrindo-se um período de maior desemprego na cidade, que dura até a próxima "safra" ou no início do próximo ano (AUTOR, 2017).

Para os fins dos objetivos da análise apresentada neste artigo, no entanto, a maior relevância dos dados até agora apresentados está diretamente relacionada com um aspecto da flexibilidade contratual existente nos mercados de trabalho de cidades médias gaúchas: a descontinuidade dos vínculos empregatícios a que estão submetidas parcelas significativas de trabalhadores. Como foi indicado ainda no quadro 01, em diferentes anos do período analisado o número de desligamentos superou o número de admissões, e mesmo em períodos em que essas últimas são maiores o número de desligamentos é muito significativo.

Para uma melhor elucidação dessas descontinuidades dos vínculos empregatícios, o quadro a seguir apresenta dados sobre os

de empregos formais existentes em janeiro de 2018 (MTE/CAGED, 2019). 
desligamentos e as admissões ocorridas nos dez municípios estudados no ano de 2017, bem como o estoque de empregos formais existentes em janeiro de 2018. A partir desses dados, então, será possível estabelecer um índice (aproximado) de rotatividade nos empregos no ano considerado, ${ }^{3}$ que é expressão da experiência de descontinuidade nos mercados de trabalho nas cidades médias gaúchas (Quadro 04).

QUADRO 04: Estoque de empregos formais em janeiro de 2018 e dinâmica de admissões e de desligamentos em 2017 nas cidades médias do Rio Grande do Sul.

\begin{tabular}{|l|c|c|c|c|}
\hline $\begin{array}{l}\text { Dados } \\
\text { Cidades }\end{array}$ & $\begin{array}{c}\text { Admissõ } \\
\text { es } \\
(2017)\end{array}$ & $\begin{array}{c}\text { Desliga } \\
\text { mentos } \\
(2017)\end{array}$ & $\begin{array}{c}\text { Estoque } \\
\text { de } \\
\text { empregos } \\
\text { em janeiro } \\
\text { de 2018 }\end{array}$ & $\begin{array}{c}\text { Desligam } \\
\text { entos/ } \\
\text { estoque } \\
\text { de } \\
\text { empregos }\end{array}$ \\
\hline Bagé & 5.773 & 5.774 & 17.295 & 33,4 \\
Bento & 15.133 & 15.472 & 38.383 & 40,3 \\
Gonçalves & 56.584 & 57.199 & 148.458 & 38,5 \\
Caxias do & 12.951 & 12.649 & 45.566 & 27,7 \\
Sul & 25.126 & 24.200 & 89.729 & 26,9 \\
Erechim & 23.480 & 24.292 & 61.417 & 39,6 \\
Passo & 14.095 & 16.174 & 41.273 & 39,2 \\
Fundo & 21.520 & 21.494 & 38.565 & 55,7 \\
Pelotas & 24.642 & 23.890 & 59.203 & 40,3 \\
Rio Grande & 6.574 & 6.138 & 19.699 & 31,1 \\
Santa Cruz & & & & \\
do Sul & & & & 37,0 \\
Santa Maria & & & 559.588 & \\
Uruguaiana & & 205.878 & 207.282 & \\
\hline Total & & & &
\end{tabular}

Fonte: MTE/CAGED, 2018. Dados organizados pelo autor.

Note-se que os índices (aproximados) de rotatividade nos empregos variaram entre os $26,9 \%$, em Passo Fundo, e os 55,7\%, em Santa Cruz do Sul. Apenas para considerar uma referência de comparação, estudo do DIESSE, tomando como base o período entre 2003 e 2015, indicou que os índices de

\footnotetext{
${ }^{3}$ Existem, pelo menos, duas formas para calcular a taxa de rotatividade de empregos num dado período. A primeira considera, num dado período, a média entre admitidos e desligados, que é dividido pelo número de trabalhadores no início ou no final do período (tomado como referência da média de trabalhadores do período em questão) e multiplicado por 100; chegando-se, então, a um índice de rotatividade. A segunda considera apenas os desligamentos que ocorreram num dado
}

rotatividade no mercado formal, em nível nacional, apresentaram a seguinte dinâmica: 42,7 em 2003; 43,6 em 2004; 44,6 em 2005; 45,5 em 2006; 46,8 em 2007; 52,6 em 2008; 49,4 em 2009; 53,2 em 2010; 54,6 em 2011; 55,2 em 2012; 54,9 em 2013; 53,9 em 2014; e 47,5 em 2015 (DIEESE, 2017, p. 82). Se consideradas esses índices como indicativos de uma média histórica, presente nos mercados de trabalho do País, observa-se que os índices apresentados na maioria das cidades médias gaúchas estão abaixo do que se observa em nível nacional.

Ainda que isso possa significar a presença de mercados de trabalho mais estáveis, onde os trabalhadores vivenciam em menor intensidade experiências de demissão e troca de locais de trabalho, não se pode relativizar a importância dos dados apresentados. Considerando a média das dez cidades médias gaúchas consideradas, observa-se que aproximadamente $37 \%$ dos trabalhadores vivenciaram, em 2017, a experiência de um desligamento e, portanto, a experiência do afastamento (voluntário ou compulsório) de um local de trabalho e a busca (ou uma situação prolongada de desemprego) de um novo local de trabalho (não necessariamente no mercado formal).

Para uma melhor compreensão de como essa dimensão da flexibilidade contratual coloca-se como experiência de descontinuidade nos mercados de trabalho e, nesse sentido, de precarização do trabalho presente nas cidades médias gaúchas, o próximo item apresenta uma análise das motivações dos desligamentos ocorridos durante o período entre 2011 e 2017.

\section{As motivações das admissões e dos desligamentos nas cidades médias gaúchas no período entre 2011 e 2017.}

período, cujo número é dividido pelo número (referência) de trabalhadores no período, obtendo-se um resultado que deve ser multiplicado por 100 (índice de rotatividade $=$ desligamentos $\div$ média de colaboradores no período $\mathrm{x}$ 100) (DIEESE, 2017). Para fins do cálculo apresentado neste texto será considerada a segunda forma, bem como o estoque de empregos em janeiro de 2018. 
Como indicado anteriormente, os dados do CAGED permitem analisar a dinâmica mensal de admissões e de desligamentos, em todos os municípios do País, tanto de forma agregada quanto de forma desagregada, identificando-se, a partir dessa última, as modalidades de admissões $e$ as modalidades de desligamentos. A partir dessa identificação é possível, então, analisar os desligamentos que ocorrem por razões vinculadas aos trabalhadores ou, então, aqueles que ocorrem por razões das empresas.

Os dois quadros a seguir apresentam esses dados, considerando as dez cidades médias investigadas e dois períodos: entre 2011 e 2014 e entre 2015 e 2017. A distinção desses dois períodos permitirá analisar as diferenças de motivações para os desligamentos entre um período de crescimento de empregos (entre 2011 e 2014) e um período de aumento no desemprego (entre 2015 e 2017) (Quadros 05 e 06).

Em relação às admissões, observa-se que a maioria é de trabalhadores que já estavam inseridos no mercado de trabalho, com uma experiência anterior de emprego. Isso ocorreu tanto no período entre 2011 e 2014 quanto no período entre 2015 e 2017. No entanto, um dado importante a ser considerado é que a participação dos primeiros empregos diminuiu no segundo período, ou seja, no período de diminuição das admissões e de aumento do desemprego. Um fenômeno, portanto, importante e, certamente, relacionado com a situação histórica dos jovens nos mercados de trabalho, mais atingidos pelo desemprego e mais vulneráveis nos períodos de estagnação econômica e de desestruturação dos mercados de trabalho (DIESSE, 2012).

QUADRO 05: Admissões e Desligamentos nas Cidades Médias Gaúchas, por Tipo de Admissão e de Desligamento (2011 - 2014).

\begin{tabular}{|l|c|c|}
\hline $\begin{array}{l}\text { Condição de Admissão } \\
\text { e de Desligamento }\end{array}$ & Números & $\%$ \\
\hline ADMISSÕES & $\mathbf{1 . 3 4 8 . 7 4 6}$ & $\mathbf{1 0 0 , 0}$ \\
Primeiro emprego & 153.194 & 11,4 \\
Reemprego & 1.104 .230 & 81,9 \\
Reintegração & 497 & - \\
\hline
\end{tabular}

\begin{tabular}{|l|c|c|}
\hline Contrato temporário & 16.080 & 1,2 \\
Transferência & $\mathbf{7 4 . 7 4 5}$ & 5,5 \\
administrativa & $\mathbf{1 . 2 9 1 . 4 5 7}$ & $\mathbf{1 0 0 , 0}$ \\
DESLIGAMENTOS & 563.979 & 43,7 \\
Sem justa causa & 11.685 & 0,9 \\
Com justa causa & 365.867 & 28,3 \\
A pedido & 255.942 & 19,8 \\
Término de contrato & 595 & - \\
Aposentadoria & 2.997 & 0,2 \\
Morte & 18.937 & 1,5 \\
Término de contrato por & 71.455 & 5,5 \\
prazo determinado & & \\
Transferência & & \\
administrativa & & \\
\hline
\end{tabular}

Fonte: MTE/CAGED, 2018. Dados organizados pelo autor.

QUADRO 06: Admissões e Desligamentos nas Cidades Médias Gaúchas, por Tipo de Admissão e de Desligamento (2015 - 2017).

\begin{tabular}{|l|c|c|}
\hline $\begin{array}{l}\text { Condição de Admissão } \\
\text { e de Desligamento }\end{array}$ & Números & $\%$ \\
\hline ADMISSÕES & $\mathbf{6 8 6 . 5 7 5}$ & $\mathbf{1 0 0 , 0}$ \\
Primeiro emprego & 51.856 & 7,5 \\
Reemprego & 571.026 & 83,2 \\
Reintegração & 277 & - \\
Contrato temporário & 17.056 & 2,5 \\
Transferência & 46.360 & 6,8 \\
administrativa & 730.454 & 100,0 \\
DESLIGAMENTOS & 376.612 & 51,6 \\
Sem justa causa & 6.552 & 0,9 \\
Com justa causa & 154.057 & 21,1 \\
A pedido & 136.460 & 18,7 \\
Término de contrato & 356 & - \\
Aposentadoria & 2.199 & 0,3 \\
Morte & 11.488 & 1,6 \\
Término de contrato por & 42.730 & 5,8 \\
prazo determinado & & \\
Transferência & & \\
administrativa & & \\
\hline
\end{tabular}

Fonte: MTE/CAGED, 2018. Dados organizados pelo autor.

Em relação aos desligamentos, os dados apresentados nesses dois últimos quadros indicam que a maioria deles ocorreram como resultado de uma motivação empresarial, seja por que os trabalhadores foram demitidos sem justa causa, seja por que estavam trabalhando temporariamente. Assim, somando os índices dos que foram desligados "sem 
justa causa" com os que foram desligados por que tinham "contrato temporário" e os que estavam atuando por um tempo determinado, chega-se aos 65\%, no período entre 2011 e 2014, e aos 71,9\%, no período entre 2015 e 2017, do total de desligamentos ocorridos em cada um desses períodos.

Esses índices ganham ainda maior importância se considerado que o primeiro período esteve caracterizado pelo aumento dos empregos, quando, inclusive, se alegava dificuldades de encontrar trabalhadores em alguns segmentos econômicos e as autoridades governamentais indicavam uma conjuntura de "pleno emprego" (DIEESE, 2017). Mesmo naquelas condições conjunturais o instrumento da demissão (sem justa causa) era amplamente utilizado pelas empresas. O que indica que essa dimensão da flexibilidade contratual é, também, uma estratégia de dominação sobre os trabalhadores, pois as empresas não se comprometem com políticas de "retenção" de seus empregados, adotam as demissões como uma estratégia de organização de seus processos produtivos, impulsionam uma cultura de insegurança junto aos trabalhadores.

Note-se, ainda, que nos dois períodos considerados existem diferenças nos índices de trabalhadores que pediram demissão: enquanto que entre 2011 e 2014 esse índice foi de 28,3\%, entre 2015 e 2017 baixou para 21,1\%. Na conjuntura favorável aos empregos, portanto, um maior número de trabalhadores pediu demissão, possivelmente na perspectiva de encontrar uma melhor ocupação, seja por causas diretamente vinculadas à remuneração do trabalho, seja em função de condições mais amplas de trabalho.

Tem-se, portanto, uma condição histórica em que essa dimensão da flexibilidade contratual, que remete diretamente às descontinuidades nas experiências de emprego (decorrente da dinâmica de admissões e de desligamentos), tem uma funcionalidade na própria reprodução do capital. As empresas encontram no trabalho temporário e de curta duração uma estratégia de organização de seus processos produtivos, atendendo suas necessidades de força-de-trabalho, sazonais ou maiores em determinados períodos do ano. Ao mesmo tempo, se desobrigam com os compromissos decorrentes da manutenção mais prolongada dos trabalhadores (investimentos em qualificação profissional, inserção em planos de carreira e melhoria salarial). Considerese, ainda, que as demissões de trabalhadores com menos de um ano de tempo de serviço, até a aprovação da reforma trabalhista de 2017, não precisava de homologação da rescisão do contrato de trabalho, o que garantia "acordos" entre empresas e trabalhadores, desonerando custos da demissão para as empresas (por exemplo, através da dispensa do pagamento da multa rescisória de $40 \%$ sobre o Fundo de Garantia por Tempo de Serviço).

Parte dos próprios trabalhadores, num contexto de baixos salários, de baixas possibilidades de ascensão profissional, de desejo de um trabalho melhor (expectativa que cresce diante da própria possibilidade limitada de ascender profissionalmente), mesmo (em alguns casos) de possibilidade de acessar determinados direitos trabalhistas (multa rescisória, seguro-desemprego), induzem suas próprias demissões.

\section{Considerações finais:}

Para parcelas crescentes das pessoas que vivem do trabalho no Brasil, a crise econômica e política que se intensificou no País a partir de 2015 (com o processo que resultou no Impeachment da Presidente da República, Dilma Rousseff) agravou uma já histórica situação de precarização no trabalho. Além da permanência de altos índices de desemprego, mudanças institucionais e políticas criaram um contexto de ainda mais insegurança nos empregos, nas rendas, nas formas de contratação do trabalho.

É a partir desse contexto histórico de precarização do trabalho que no presente artigo foram analisadas as dinâmicas de admissões e de desligamentos nos mercados de trabalho das cidades médias do Rio Grande do Sul. Além do acompanhamento dessas dinâmicas no período entre 2011 e 2017, a análise contemplou também as motivações dos desligamentos ocorridos, numa 
perspectiva de melhor entender essa dimensão da flexibilidade contratual existentes nos mercados de trabalho.

A investigação mostrou que a dinâmica de admissões e de desligamentos nas cidades médias gaúchas acompanhou tendências observadas em nível nacional e, nesse sentido, se o período entre 2011 e 2014 foi de crescimento dos empregos formais, a partir de 2015 um quadro de crescimento de desemprego se configurou. Nesses dois períodos, no entanto, os índices de desligamentos de trabalhadores manteve-se elevado, revelando-se altos índices de rotatividade no trabalho.

Ainda que os resultados apresentados indiquem a necessidade de novas pesquisas visando aprofundar a análise das razões dos desligamentos, foi possível indicar que as demissões ocorrem, principalmente, por razões vinculadas às estratégias das empresas. Nesse sentido, a dinâmica de admissões e desligamentos, na qual se explicita altos índices de desligamentos, precisa ser entendida nos quadros da organização empresarial dos processos produtivos e de controle sobre o uso da força-detrabalho.

Para os trabalhadores, a dinâmica de admissões e de desligamentos presentes nas cidades médias gaúchas expressa uma condição histórica de flexibilidade contratual, da qual resultam experiências descontínuas nos mercados de trabalho, períodos de emprego lado a lado aos períodos de desemprego, comprometimento de suas rendas, dificuldade de planejamento de suas vidas profissionais, uma sempre frágil inserção em comunidades de trabalho.

\section{Referências}

1 ANTUNES, R. O privilégio da servidão: o novo proletariado de serviços na era digital. São Paulo: Boitempo, 2018.

2 BRASIL. MINISTÉRIO DO TRABALHO E EMPREGO. Cadastro Geral de Empregados e Desempregados. http://bi.mte.gov.br/bgcaged/caged perfil munici pio/index.php. Consulta em: 19 dez. 2018.

3 AUTOR. Dinâmicas Regionais de Desenvolvimento, Trabalho e Organização dos Mercados Urbanos de Trabalho: uma Análise a

Partir de Cidades Médias do Rio Grande do Sul. Santa Cruz do Sul, Redes, v. 22, p. 343-357, 2017. desenvolvimento subnacional no Rio Grande do Sul: uma análise a partir dos posicionamentos da FIERGS em relação ao salário mínimo estadual durante o governo de Yeda Crusius (2007 - 2010). Rio de Janeiro, Planejamento e Políticas Públicas, v. 46, p. 161-180, 2016.

5 CHIAVENATTO, I. Gestão de pessoas e o novo papel dos recursos humanos nas organizações. Rio de Janeiro: Elsevier,2004.

CONSOLIDAÇÃO DAS LEIS DO TRABALHO (CLT). Brasília: Senado Federal/Coordenação de Edições Técnicas, 2017.

7 DIEESE (Departamento Intersindical de Estatística e Estudos Socioeconômicos). A situação do trabalho no Brasil na primeira década dos anos 2000. São Paulo: DIEESE, 2012. . Movimentação no mercado de trab rotatividade, intermediação e proteção ao emprego. São Paulo: DIEESE, 2017.

9 IBGE (INSTITUTO BRASILEIRO DE GEOGRAFIA E ESTATÍSTICA). Estimativa de população 2017. Rio de Janeiro: IBGE, 2017. In: https://cidades.ibge.gov.br/xtras/temas.php?cod mun=0\&idtema=130. https://www.ibge.gov.br/. Consulta em: 20 dez. 2018.

11 PEREIRA, F. M., LEMOS, M. B. Cidades médias brasileiras: características e dinâmicas urbanoindustriais. Pesquisa e Planejamento Econômico (PPE), Brasília, IPEA, v. 33, n. 1, p. 127-165, abr. 2003.

12 SPOSITO, M. E. B. (org.). Cidades Médias: espaços em transição. São Paulo: Expressão Popular, 2007.

13 SOUEN, J. A.; CAMPOS, G. C. de S. Da euforia ao retrocesso: o comportamento do emprego formal no Brasil no período recente. São Paulo, Revista Pesquisa \& Debate, v. 28, n. 1 (51), p. 4262, jul. 2017. 